\title{
MONITORING AND PREDICTING MASONRY'S CREEP FAILURE WITH THE ACOUSTIC EMISSION TECHNIQUE
}

\author{
Els Verstrynge ${ }^{\mathrm{a}, *}$, Luc Schueremans ${ }^{\mathrm{a}}$, Dionys Van Gemert ${ }^{\mathrm{a}}$, Martine Wevers ${ }^{\mathrm{b}}$ \\ ${ }^{\mathrm{a}}$ Department of Civil Engineering, KULeuven, Kasteelpark Arenberg 40, bus 2448, \\ 3001 Heverlee, Belgium \\ ${ }^{b}$ Department of Metallurgy and Materials Engineering, KULeuven, Kasteelpark \\ Arenberg 44, 3001 Heverlee, Belgium \\ * Corresponding author: \\ Tel: ++32 (0)16 32 19 87, Fax: ++32 (0)16 3219 76, \\ E-mail: els.verstrynge@bwk.kuleuven.be
}

Original article can be found on http://dx.doi.org/10.1016/j.ndteint.2009.03.001 and was published as: Verstrynge, E., Schueremans, L., Van Gemert, D., Wevers, M. (2009). Monitoring and predicting masonry's creep failure with the acoustic emission technique. NDT \& E international, 42 (6), 518-523: 2009

\begin{abstract}
The applicability of the acoustic emission (AE) technique to detect unstable damage accumulation in masonry, subjected to the creep failure mode, is investigated during short-term and long-term creep tests on masonry specimens. The damage accumulation is quantified using the results of the monitored AE event rates, which evolve as a bathtub shaped curve during the last phase of the creep tests. The bathtub curves are described using the Weibull function and a relation is found between the detected $\mathrm{AE}$ event rate and the time to failure of the specimens.
\end{abstract}

Keywords: damage accumulation, acoustic emission, masonry, creep

\section{Introduction}

Within civil engineering practice, the Acoustic Emission (AE) technique is a widely applied non-destructive technique for the detection of damage onset and growth in concrete structures $[1,2]$. The AE technique is used to monitor the high frequency energy waves, which are emitted by the material when damage occurs. Consequently, different phases of the cracking process and different failure modes can be detected. As the arrival times of the $\mathrm{AE}$ waves at different sensors are linked to the propagation speed inside the material, algorithms can be used to locate the emitting source. Other applications of the acoustic emission technique include damage detection in metals, composites, rocks and to a small extent wood $[1,3]$.

The work presented here focuses on the applicability of the AE technique in order to assess damage accumulation in masonry, subjected to the creep failure mode. The use of AE monitoring in masonry structures is highly complicated, as attenuation and sound propagation are dependent on the heterogeneity of the material (including the interface between bricks and mortar, but also cracks and cavities in existing 
structures). This makes source location in masonry structures rather difficult. Attempts were made by Carpinteri [5], involving the location of cracks during an onsite monitoring campaign. Although a large amount of AE events were detected, only a small percentage of them could be located. Damage location in masonry arch bridges was performed by Tomor [6], by simply applying a large set of AE sensors and identifying the sensors at which most damage was detected.

The consequences of the heterogeneity of masonry are not only restricted to the location of the AE sources. The presence of voids, cracks and cavities does also influence the AE detection itself. The AE waves, generated at the other side of a large crack to which the sensors are placed, will generally not be detected by the AE sensors. This, for example, would be the case between the disconnected layers of a multiple-leaf wall, which is often encountered in historical masonry structures. Therefore, the location of the sensors has to be chosen carefully and the quality of the surrounding masonry has to be taken into account.

The aim of the presented research is to check the applicability of the AE technique to detect unstable damage accumulation in masonry. The research is performed at the Reyntjens laboratory of the KULeuven under controlled conditions. Possibilities are investigated to efficiently obtain data during long-term and periodical monitoring.

The background of this research is the collapse of several historical masonry structures over the past decades due to time-dependent deformations caused by high, sustained loading [7,8]. One of these structures is the Maagden tower, which partially collapsed on 1st of June, 2006 (see Fig. 1). No sudden disturbance of the acting forces, such as an earthquake, could be pointed out as having caused the collapse. The tower was composed of three-leaf masonry in sandstone, which appeared to be in a bad condition. A high dead load acted on the base of the tower, especially in the area where the cross-section of the wall was reduced by a staircase opening. It is at this point that the wall collapse was triggered [9].

These events have urged the research for non-destructive techniques which are able to detect unstable damage accumulation in masonry structures. 


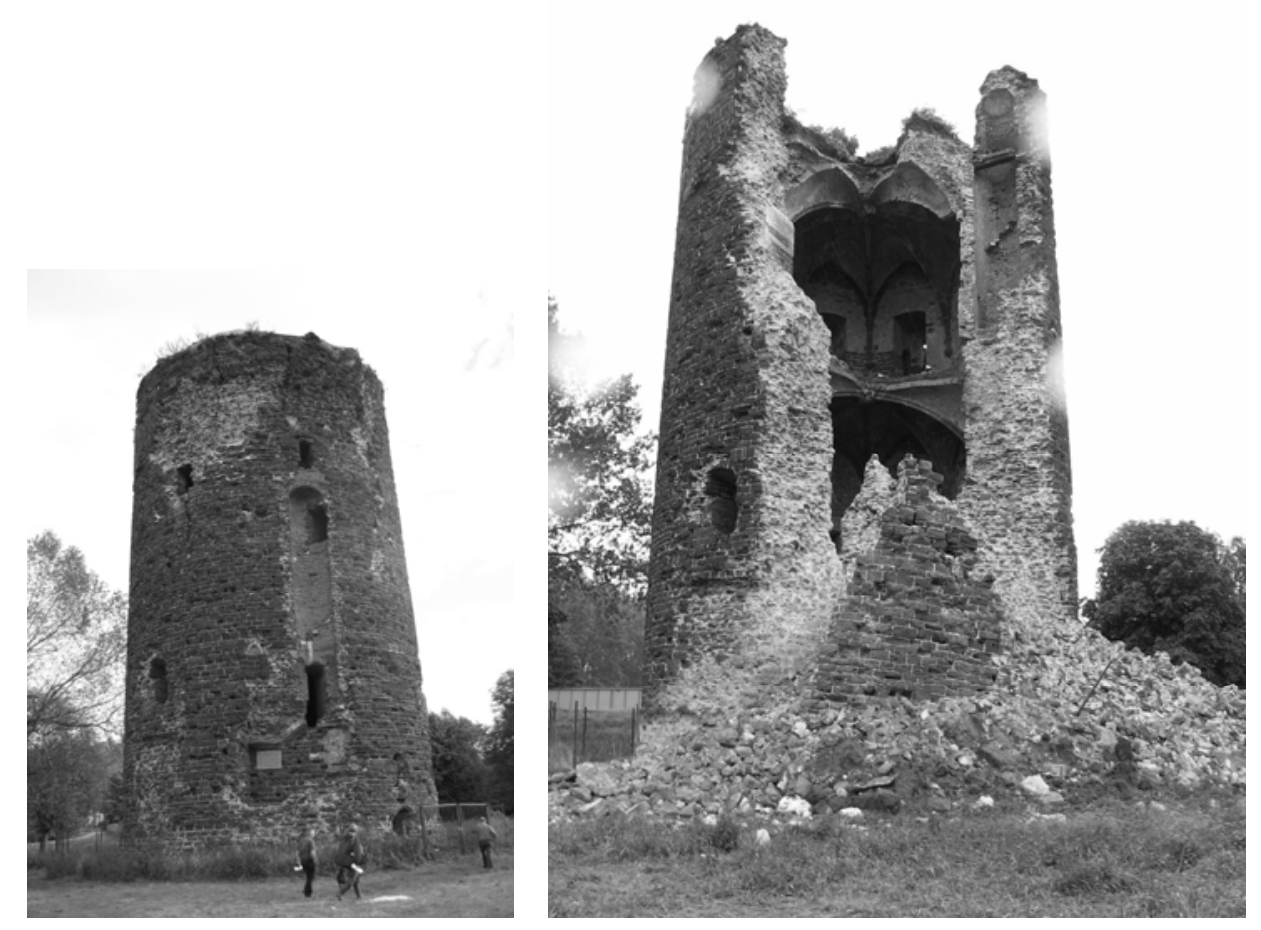

Fig. 1. Maagden tower at Zichem, Belgium, before and after collapse (June 2006)

The AE technique has already proven to be a valuable technique to obtain qualitative data regarding the damage processes in a range of building materials, especially in concrete research. The question is often how to quantify this damage accumulation and translate it into levels of deterioration, each with their appropriate conclusion on the action which has to be undertaken to guard the structures' safety. Quantification of damage by means of AE data has been addressed for example by Eberhardt [3] for brittle fracture in rock. Ohtsu [2] reviewed different qualitative and quantitative methods for processing of AE monitoring results, mostly in concrete, and Carpinteri [4] related the AE output during compressive testing with time-dependent damage processes in masonry towers.

\section{Experimental set-up}

The discussion in the presented work combines the results of two test programs. Both test programs include deformation and acoustic emission monitoring of masonry specimens during creep tests. One series of experiments focuses on long-term creep testing, while the second experimental program concerns different short-term creep tests, also called accelerated creep tests.

\subsection{Materials and specimens}

For all masonry specimens, the same relatively low-strength bricks were chosen, type Spanish red, with dimensions $188 * 88 * 48 \mathrm{~mm}$ (module M50). For the first test series, the long-term creep tests, these bricks were combined with a range of different mortar types: cement mortar, air-hardening lime mortar, hydraulic lime mortar and a blended cement-lime mortar. The specimens were small masonry columns, with dimensions 
$19 * 29 * 85 \mathrm{~cm}(1 * b * h)$, composed of 14 brick layers, with three bricks per layer and a mortar thickness of $1 \mathrm{~cm}$. The height of the masonry wallets is at least two times larger than the thickness to assure a uniaxial stress distribution in the middle of the specimens.

For the short-term creep tests, masonry specimens with dimensions $19 * 19 * 60 \mathrm{~cm}$ $(1 * b * h)$ were constructed. The columns were composed of 10 brick layers, with two bricks per layer and an air-hardening lime mortar. Half of the number of specimens was subjected to accelerated carbonation (B-type specimens). The other half of the specimens were allowed to carbonate naturally and, consequently, were not fully carbonated at the time of testing (A-type specimens). The smaller size of the specimens was chosen due to technical restrictions of the test equipment.

\subsection{Test set-up}

Both types of creep tests, short-term as well as long-term, follow the same basic principles considering their test set-up. A stepwise increasing, axial load is applied on the specimens and the damage evolution in time is detected by monitoring the deformations and acoustic emissions as a function of time and stress level. A typical loading path, followed during an accelerated creep test (ACT) is indicated in Fig 2. The time interval between two stress increase steps is three hours. During the longterm creep tests, at least a two months interval was chosen. The stress levels are calculated as a certain percentage of the average compressive strength $\left(f_{c}\right)$. The compressive strength is obtained as the average value of the result of at least three monotonic compressive tests for each mortar composition respectively.

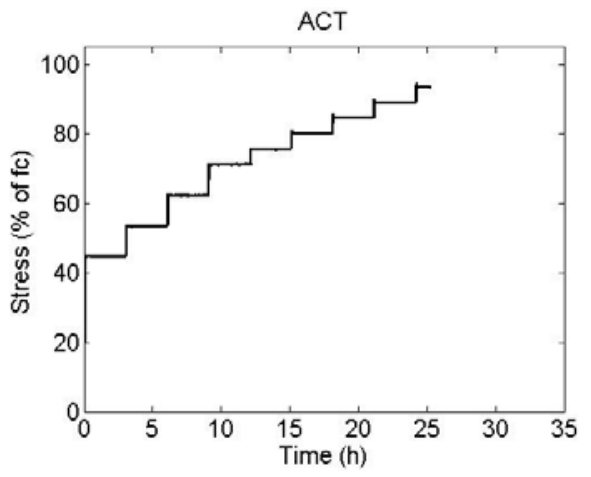

Fig. 2. Typical stress path followed during short-term creep test

The duration of the creep test imposes certain restrictions on the testing and monitoring equipment used. For the accelerated creep tests, a test device, type Schenck Trebel RM 100, was used to apply the load. Additionally, one horizontal and one vertical Linear Voltage Displacement Transducers (LVDT) was installed on each side of the specimen (see Fig. 3a) to continuously monitor the strain evolution. The overall deformations were calculated as an average of all sides. Due to the extended duration of the long-term creep tests, separate steel frames were constructed for each test specimen and hydraulic jacks were used to apply the load (Fig. 3b). Removable mechanical strain gauges were used to measure the deformations periodically. On 
each side of the masonry test specimens, four horizontal and six vertical measuring bases were installed.
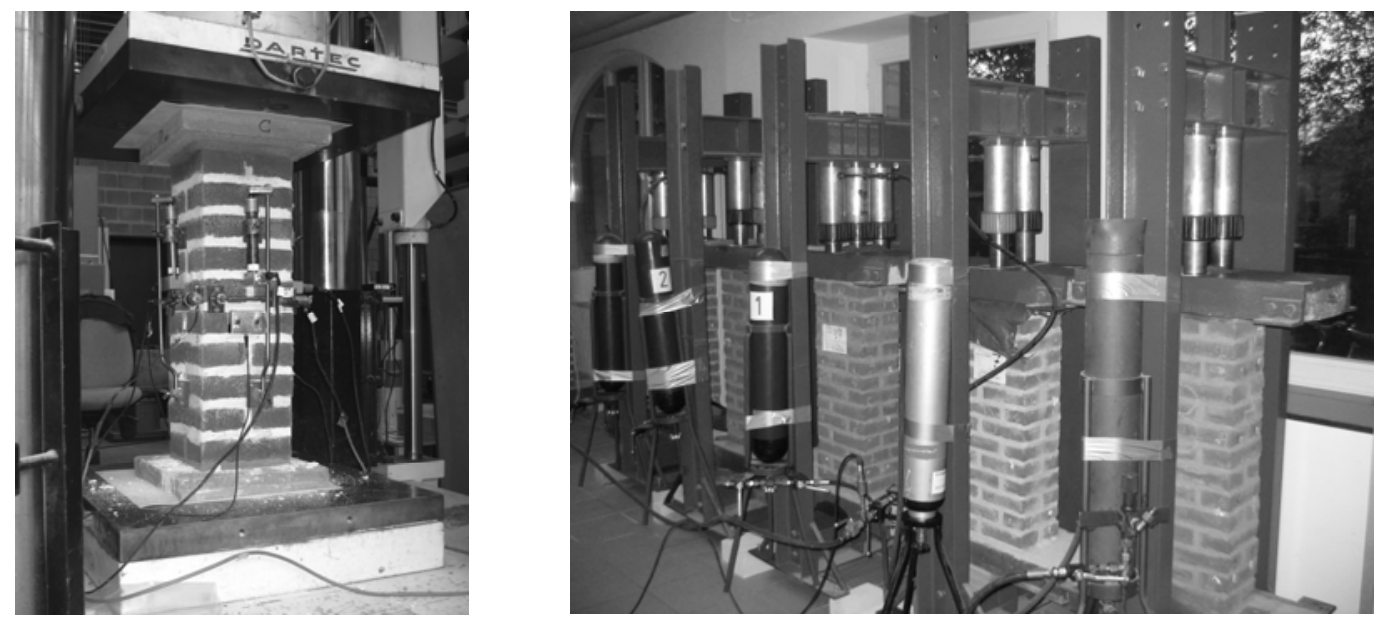

Fig. 3. Typical short-term (a) and long-term (b) creep test set-up

\subsection{Acoustic emission monitoring}

The monitoring of acoustic emissions during the creep tests enables to quantify the damage events from which they are originated. AE signals are high frequency energy waves, which are emitted by the material when damage, such as crack initiation and propagation, occurs. Also friction phenomena in existing cracks can be sources of AE events. In the considered axial compressive tests, tensile forces are introduced in the bricks due to the higher deformability of the mortar joints, which have a larger lateral expansion than the bricks. These tensile forces introduce vertical cracks in the bricks, which typically produce a large amount of AE signals.

During all creep tests, the acoustic emissions were monitored by placing two sensors on each specimen, one sensor in the middle of opposite sides. The AE monitoring was performed with a Vallen AMS-3 and AMSY-5 system. The first system is a two channel set-up, whereas the AMSY-5 system has four channels. This enables the simultaneous monitoring of two specimens, which is an advantage especially for the long-term tests. The AE sensors are attached to the masonry by means of a thin metal plate which is carefully glued on the surface. This does not have significant effects on the $\mathrm{AE}$ event detection, and has the advantage of providing a fixed place to reattach the sensors during periodic monitoring. A vacuum grease is used as a couplant in between the sensor and the metal plate. The sensors had a frequency range of 250$700 \mathrm{kHz}$, with a resonance at $375 \mathrm{kHz}$. In order to filter out the continuous lowamplitude background noise, a threshold is defined and only waves passing this amplitude-threshold are detected as an AE event. The typical features of an AE signal are indicated in Fig. 4a. The preamplifier gain is set to $34 \mathrm{~dB}$ and a threshold level of $34.5 \mathrm{~dB}$ is applied. A low value could be chosen for the threshold level, due to the limited amount of background noise in the laboratory.

The amplitude in $\mathrm{dB}$ is calculated according to: 


$$
d B=20 \log \left(\frac{\operatorname{Voltage}(\mu V)}{1 \mu V}\right)
$$

The average wave velocity inside the accelerated creep test specimens ranges from $800 \mathrm{~m} / \mathrm{s}(120 \mathrm{~m} / \mathrm{s}$ standard deviation) for the not fully carbonated masonry to 1057 $\mathrm{m} / \mathrm{s}(180 \mathrm{~m} / \mathrm{s}$ standard deviation) for the fully carbonated masonry. The wave velocity is calculated using the distance between the source and the sensors and the travel time of the wave between the two sensors. So it also depends strongly on the threshold level, as the arrival time of a wave at a specific sensor is marked by the moment the threshold is exceeded. This dependency of the wave speed on the threshold was checked on two specimens and is indicated in Fig. 4b. The break of a pencil lead can be detected up to $30 \mathrm{~cm}$ from the sensor; again this distance depends on the lay-out of the bricks, the quality of the mortar-brick connection and the coherence of the masonry in general.

These preliminary verifications indicate that the majority of the damage sources in the specimen can be monitored by placing two sensors in the middle (as the height of the specimens is $60 \mathrm{~cm}$ ). For all creep tests, a threshold level of $34.5 \mathrm{~dB}$ is used. The complexity of the material lay-out and wave propagation makes source location impracticable.

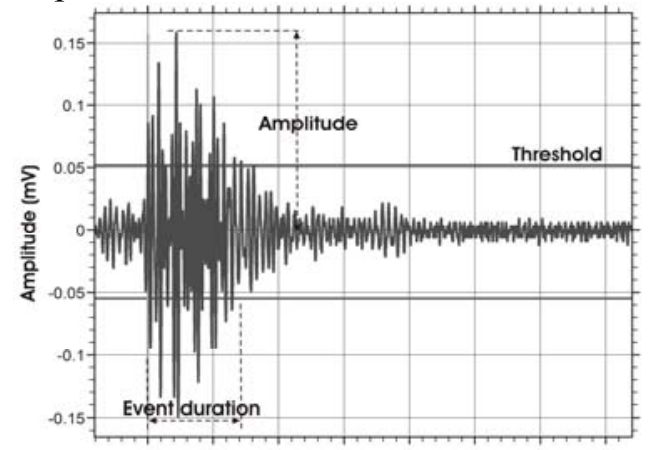

Fig. 4a. Main features of an AE signal (burst type)

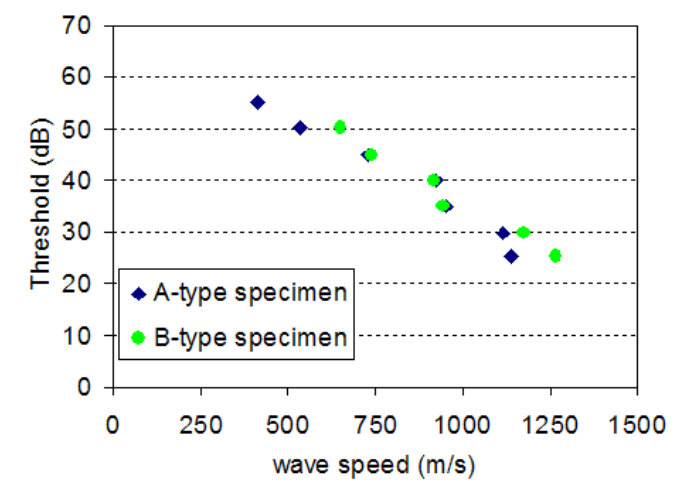

Fig. 4b. Dependency of wave propagation speed on threshold level for uncarbonated (Atype) and fully carbonated (B-type) specimens

\section{Monitoring results}

Masonry specimens, when subjected to high sustained loading, exhibit a typical, three-phase creep behaviour: a primary creep phase with decreasing damage rate, a second phase with constant rate (also called steady-state creep) and a tertiary phase with increasing damage rate, during which unstable damage accumulation leads to failure of the specimen. As this work deals with the monitoring and prediction of failure of masonry subjected to high, sustained stresses, the main focus will be on the last step of the creep tests, during which all phases of the typical creep behaviour are experienced. More over, only the specimens which exhibited a tertiary creep phase, and therefore did not fail during or immediately after stress increase, will be of use for the discussion. This obviously limits the number of useful test results. 


\subsection{AE detection before failure}

The result of a final stage of a long-term creep test is presented in Fig. 5a. A full description of the results of these tests was published before in [10]. The graph indicates the event rate (in events/minute) as a function of time. The peak value at the beginning of the curve indicates the moment at which the stress was increased to $75 \%$ of the compressive strength of the specimen. It has to be noticed that this compressive strength is the average strength obtained from compressive tests on three masonry specimens with the same composition. The stated $75 \%$ should therefore be seen as an estimated value. The stress path is indicated in Fig. 5 with a dotted line.

After the stress increase step, the event rate decreases to a low, almost constant value (indicated in Fig. 5 with a horizontal arrow), while the stress level is kept at a constant value. After five days, the event rate increases again and keeps rising until the specimen finally fails about one week after the stress increase. The moment of failure is indicated by the second peak value in the graph. As the event rate started increasing again about 50 hours before failure of the specimen, the unstable damage increase, which was a warning of the failure, could be detected more than two days before the actual collapse occurred.

Column 28 - long term creep test

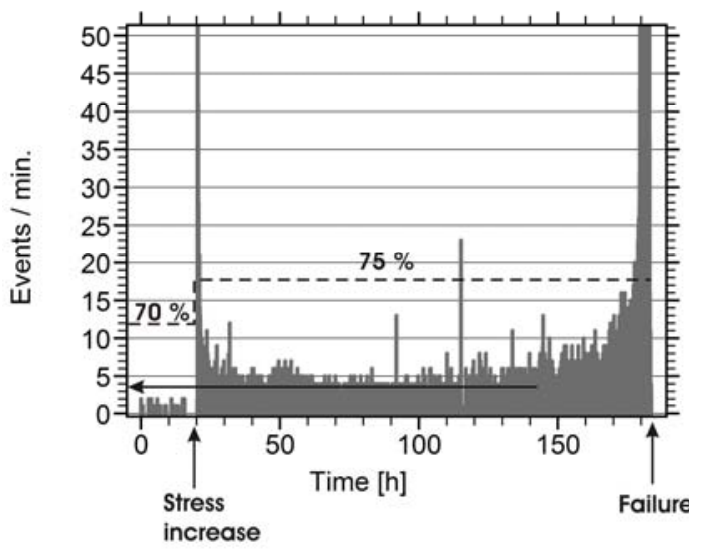

Column A9 - last loading step

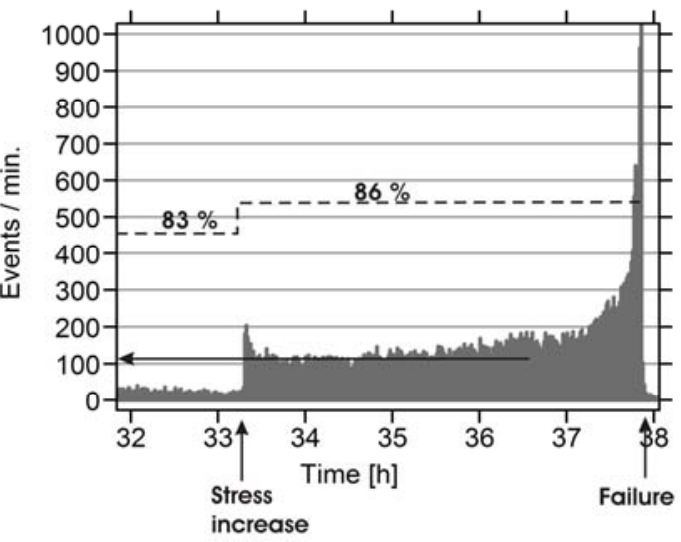

Fig. 5. AE event rate during final phase of long-term (a) and short-term (b) creep test

For comparison, the result of a final stage of a short-term creep test is presented in Fig. 5b. In order to compare the results of this short-term creep test with the long-term test in Fig. 5a, the event rate is indicated on the same scale, in events $/ \mathrm{min}$. Again, the stress path is indicated with a dotted line and the stress is increased from $83 \%$ to $86 \%$ of the average compressive strength, obtained from compressive tests on similar specimens. The appearance of the curve is clearly related to the results of the longterm creep test. However, the secondary stage, with a low constant value, appears to be much shorter and shows a higher event rate. The acquisition of these results is rather complex, as many specimens do not show a significant tertiary creep phase during the short-term creep test, but fail during the stress increase itself. Other specimens fail shortly after the stress increase. They do demonstrate a resulting graph comparable with the ones shown here, but the secondary stage decreases and often, 
only a small drop in event rate is visible in between the two peak values. The duration of the secondary stage and the minimum value for the event rate obtained appear to be correlated with the time to failure.

\subsection{Bathtub curve}

The graph presenting the event rate as a function of time (Fig. 5a and 5b) can be described as a bathtub curve [12], as presented in Fig. 6. In reliability analysis, bathtub curves are often used to present the hazard rate in function of time. The curve has a first stage with a decreasing failure rate, known as the infantile or early-life failures, where the system is adopting to the new situation. The second stage shows a constant hazard and the third phase, also called the wear-out phase, an increasing failure rate. The bathtub curve has a broad field of application and can be described by the Weibull function:

$$
f(t)=\frac{\beta}{\eta}\left(\frac{t-\gamma}{\eta}\right)^{\beta-1} e^{-\left(\frac{t-\gamma}{\eta}\right)^{\beta}}
$$

With

$$
\begin{aligned}
& \beta=\text { shape parameter } \\
& \eta=\text { scale parameter } \\
& \gamma=\text { location parameter }
\end{aligned}
$$

The shape parameter, $\beta$, also called the Weibull slope parameter determines the slope of the Weibull probability density function (pdf) and enables the three stages of the bathtub curve to be described (see Fig. 6):

- $\beta<1$ : describe a decreasing failure rate

- $\beta=1$ : describe a constant failure rate, the Weibull pdf reduces to an exponential distribution

- $\beta>1$ : describe an increasing failure rate

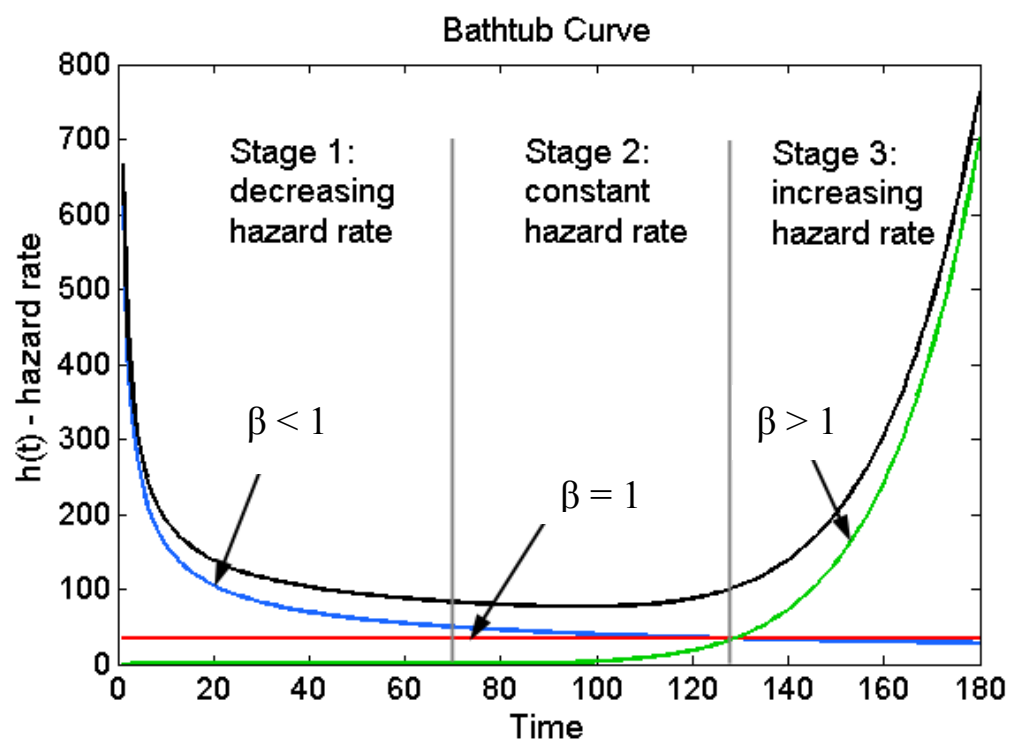

Fig. 6. Bathtub curve 
The hazard function is given by:

$$
h(t)=\frac{\beta}{\eta}\left(\frac{t-\gamma}{\eta}\right)^{\beta-1}
$$

For the second stage of the bathtub curve $(\beta=1)$, the hazard rate reduces to the inverse of the scale parameter $\left(\frac{1}{\eta}\right)$, which corresponds to the frequency of the exponential distribution.

In our case, this frequency or failure rate can be translated into the $\mathrm{AE}$ event rate. Instead of considering the failure of a certain product, component or structural element, the failure can be seen as a local phenomenon. Local damage occurs inside the material when an AE event is detected. The increase of these local damage points will eventually lead to failure of the material.

The duration and the hazard rate of the second stage of the bathtub curve depend on the stress level. The higher the stress level, the higher the frequency of local failures $\left(\frac{1}{\eta}\right)$ and the shorter the duration of this stage will be. This can be clearly observed from the typical diagram in Fig. 7. When higher sustained stresses are imposed on the masonry, shorter and steeper creep curves are obtained. This is translated into a shorter second stage of the bathtub curve as the latter can be seen as the derivative of the creep curve. The Y-axis in Fig. 7 indicates strain, as well as cumulative AE events or damage accumulation. As was indicated before in [10], there is a straightforward relation between these observable parameters. To quantify the dependence between time and hazard rate for the presented creep tests, the relation between the AE event rate during the second phase and the time to failure of the specimens was investigated.

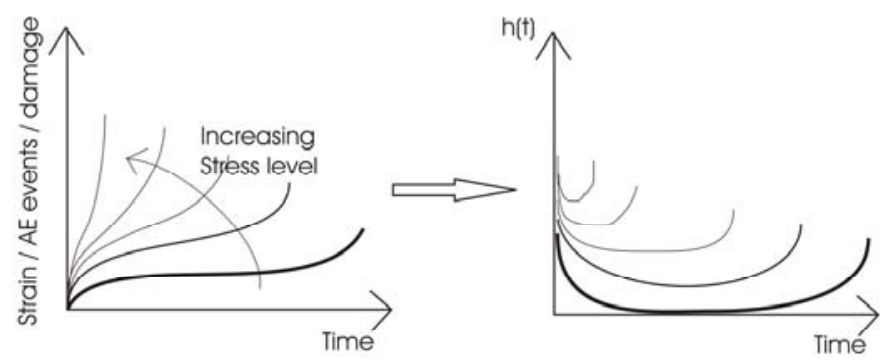

Fig. 7. Derivation of bathtub shaped curve from creep curves

\subsection{Failure prediction}

During the creep tests, 9 specimens showed a tertiary creep phase and failed during the constant stress interval instead of during the stress increase step. Of this amount, 7 specimens were part of the short-term creep test program and 2 specimens were part 
of a long-term creep test program. The minimum event rate during the secondary phase of these tests was plotted in relation to the failure time $\left(\mathrm{T}_{\mathrm{f}}\right)$ of the specimens. The results are shown in Fig. 8.

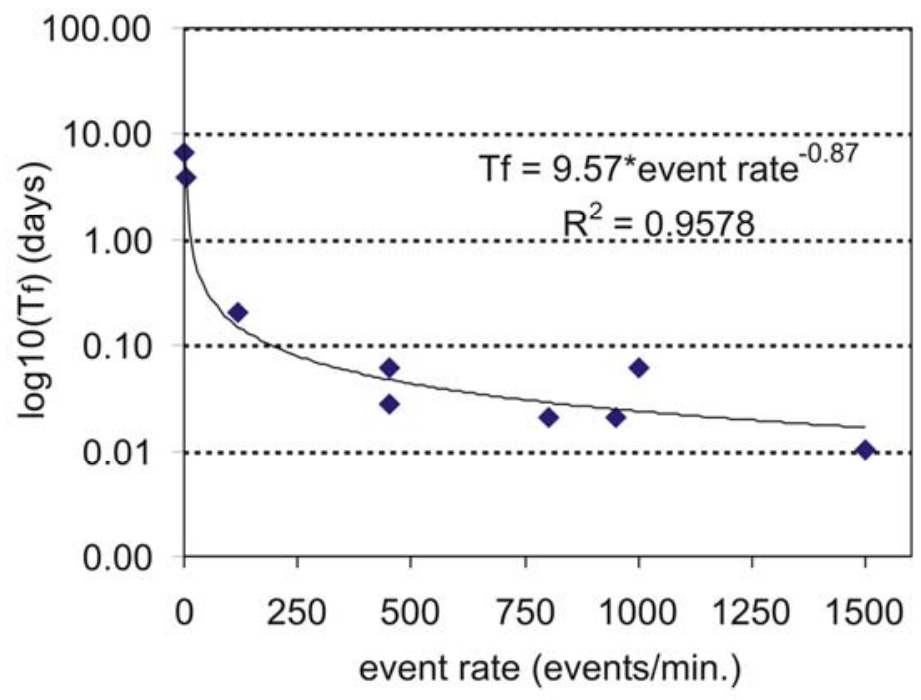

Fig. 8. Relation between time to failure $\left(\mathrm{T}_{\mathrm{f}}\right)$ and minimum AE event rate

A power law relation is found between the minimum event rate during the second stage of the bathtub curve and the time to failure of the specimen after the last stress increase step. The largest time to failure obtained during the laboratory tests was approximately one week. The relationship found here could be extrapolated to longer failure times or, in other words, to masonry subjected to lower stress levels. Unfortunately, two questions rise when this extrapolation would be done in order to assess the failure time while monitoring a structure.

The first question is whether this extrapolation is permitted, as well in time (lower stress levels) as in space (larger structures). The latter issue could be addressed by checking the maximum distance between source and sensors and the use of guarding sensors to obtain a comparable monitoring area as during the laboratory tests. Knowledge on the former issue should be obtained with more long-term creep data (a new long-term creep test program has been set up) and experience from on-site monitoring.

The second question is rather a remark considering the power law relation: if a failure time of 6 months or more is expected, the power law relation predicts an event rate of less than 50 events per day. It is difficult to obtain this accuracy during an on-site monitoring, due to background noise and external excitations of the structure, as the structure can not be isolated and kept under constant environmental conditions as a specimen tested in laboratory conditions. And the event rate will even decrease further when failure times of several years are expected. This can be explained using the scheme in Fig. 7. When the event rate, or in other words the slope of the creep curve decreases, the value of the bathtub curve during the second stage approaches zero. When on the other hand the tertiary creep phase is reached, it can be anticipated that an increase in damage accumulation can always be detected by monitoring the $\mathrm{AE}$ event rate. 


\section{Conclusions}

To assess ongoing damage accumulation in masonry, acoustic emissions were monitored during short- and long-term creep experiments. The creep tests have shown that the $\mathrm{AE}$ technique is a very valuable tool to monitor progressing damage in masonry and could even be used as a warning system for masonry structures, subjected to the creep failure mode.

A method for quantification of the failure time, based on the monitored event rate was presented. Although, it was noticed that this quantification, based on the bathtub curve theory and the power law relation between event rate and failure time, still includes some drawbacks. An extension of the power law behaviour towards longer failure times results in low acoustic emission levels to be monitored, which will complicate the analysis. It has also to be kept in mind that the reported event rates are average values, measured over a longer period of time. Too short periodical in-situ monitoring could therefore result in inaccurate average values, as no acoustic emissions will be detected when there is no damage occurring during the monitoring period. As the execution of creep tests requires rather complicated experiments of long duration, limited data sets are available, which makes it difficult to determine a confidence interval for the presented model. Further research will focus on obtaining a more extensive data set of masonry specimens, failing after exhibiting a tertiary creep phase.

As stated in the introduction, the link between damage detection and quantifying the deterioration rate is a complex issue, which will remain one of the main points of focus during present and future research, as well for creep damage in masonry as for other AE applications.

\section{Acknowledgements}

The authors express their thanks to the Flemish Fund for Scientific Research (FWO) for the doctoral grant, offered to Els Verstrynge.

\section{References}

[1] Grosse, C.U., Ohtsu, M. (eds.), Acoustic Emission Testing - Basics for research - Applications in Civil Engineering. 2008. 415p.

[2] Ohtsu M, Tomoda Y. Acoustic emission techniques for crack detection and damage evaluation. In Binda L, di Prisco M, Felicetti R. (eds.) Proc. of 1st Int. Rilem Symposium on Site Assessment of Concrete, Masonry and Timber Structures, Varenna, Italy, 1-2 Sept 2008. p. 191-200.

[3] Eberhardt E, Stead D, Stimpson B. Quantifying progressive pre-peak brittle fracture damage in rock during uniaxial compression. Int. J. Rock Mech. \& Min. Sci 1999; 36:361-380.

[4] Carpinteri A, Lacidogna G. Damage evolution of three masonry towers by acoustic emission. Engineering structures 2007; 29: 1569-1579.

[5] Carpinteri A, Lacidogna G, Manuello A, Binda L. Monitoring the structures of the ancient temple of Athena incorporated into the cathedral of Syracuse. In Masia M, Totoev Y, Page A, Sugo H (eds.) Proc. of the 14th Int. Brick and Block Masonry Conference, Sydney, 17-20 Febr. 2008, abstract p. 32. 
[6] Tomor A.K, Melbourne C. Monitoring masonry arch bridge response to traffic loading using acoustic emission techniques. Proc. of the 5th int. conference on arch bridges, Madeira, Portugal, 12-14 september 2007. p. 281-288.

[7]Binda L, Gatti G, Mangano G, Poggi C, Landriani G.S. The Collapse of the Civic tower of Pavia: A survey of the materials and structure. Masonry Int. 1992; 6(1): 633-642.

[8] Ignoul S, Schueremans L, Binda L, et al. Creep behavior of masonry structures - failure prediction based on a rheological model and laboratory tests. In Lourenço PB, Roca P, Modena C, Agrawal S.

(eds.) Proc. of the 5th int. seminar on structural analysis of historical constructions 2006; 2: 913-920.

New Delhi 2006.

[9] Schueremans L, Ignoul S, Figeys W,Verstrynge E, Depickere W, Van Gemert D, Van Balen K. Preand post collapse emergency interventions on historic load-bearing structures - case studies in Belgium, Historic Structures 11th International Scientific Conference, Cluj Napoca, 25-27 October 2007. p. 25-55.

[10] Verstrynge E, Ignoul S, Schueremans L, Van Gemert D, Wevers M. Application of the acoustic emission technique for assessment of damage-accumulation in masonry. Int. Journal for Restoration of Buildings and Monuments, Int. Zeitschrift für Bauinstandsetzen und Denkmalpflege, Aedificatio Publishers, Freiburg 2008, 14(3):167-178.

[11] Verstrynge E, Ignoul S, Schueremans L, Van Gemert D. Modelling of damage accumulation in masonry subjected to a long-term compressive load. In D'Ayala D, Fodde E. (eds) Proc. of the 6th Int. Seminar on Structural Analysis of Historical Constructions, Bath, 2-4 July 2008. p. 525-532.

[12] Melchers R. Structural Reliability, analysis and prediction. Wiley \& Sons (eds.), 1999. 